\title{
NEUROSCIENCE
}

\section{Characterizing a TDP-43 mouse for ALS research}

Watkins, J.A., Alix, J.P., Shaw, PJ. and Mead, R.J. Sci. Rep. 11, 16659 (2021).

Since researchers first linked mutations in the gene superoxide dismutase 1 (SOD1) to the neurodegenerative disease Amyotrophic Lateral Sclerosis (ALS) in 1993, much effort has gone into creating SOD1 mouse models; work with these mice has however failed to translate to the clinic. Among patients, SOD1 mutations only turn up in about $10 \%$ of familial cases, which only account for $1 \%$ of all ALS cases. Researchers need to be looking elsewhere too.

"In an ideal world, we would have a panel of ALS models so that if we were testing a compound or looking for a particular biomarker, we could look in each of the models in the hope that, broadly speaking, we're covering most ALS patients," says Jodie Watkins, currently a scientist at biopharmaceutical company MSD. While completing her PhD in Richard Mead's lab at the University of Sheffield, she revisited a non-SOD1 model of ALS: the TDP- $43^{\mathrm{Q} 331 \mathrm{k}}$ transgenic mouse, because transactive response-DNA-binding protein
43 (TDP-43) pathologies turn up in $97 \%$ of human cases. "If you can represent that in a model, you're hopefully going to represent most of the patient population," says Watkins.

The TDP-43 ${ }^{\text {Q331k }}$ transgenic mouse had been developed in 2013 but when it was deposited with the Jackson Laboratory, it was crossed onto a different background strain - from a C57BL/6J to a C57BL/6N. When Watkins and her colleagues phenotyped TDP- $43^{\mathrm{Q} 331 \mathrm{k}}$ mice on the $6 \mathrm{~N}$ background, they found some reassuring replication in motor deficits observed in mutant animals compared to wild-type controls. There was however a surprise. "The mice put on lots of weight," says Watkins. "This hadn't been previously reported, so we assume it was due to the different genetic backgrounds."

Weight gain isn't common in ALS - the opposite tends to be true - but Watkins posits the mice may have a frontotemporal dementia (FTD) phenotype; hyperphagia and weight gain have been observed in patients with FTD. More work is needed to confirm, but it's an intriguing observation "about $50 \%$ of ALS patients have cognitive deficits," says Watkins; a model that recapitulates that would offer additional experimental readouts to see if treatments are having an effect.

In addition to characterizing the TDP- $43^{\mathrm{Q} 331 \mathrm{k}}$ mouse, the lab took care to refine details for others who may be interested in exploring this model of ALS. They performed a power analysis that indicates a smaller number of these mice are needed, and they also conclude that length of the experiment need not extend beyond 6 months - going to 10 didn't add significant additional information.

Ellen P. Neff

Published online: 13 September 2021 https://doi.org/10.1038/s41684-021-00856-2

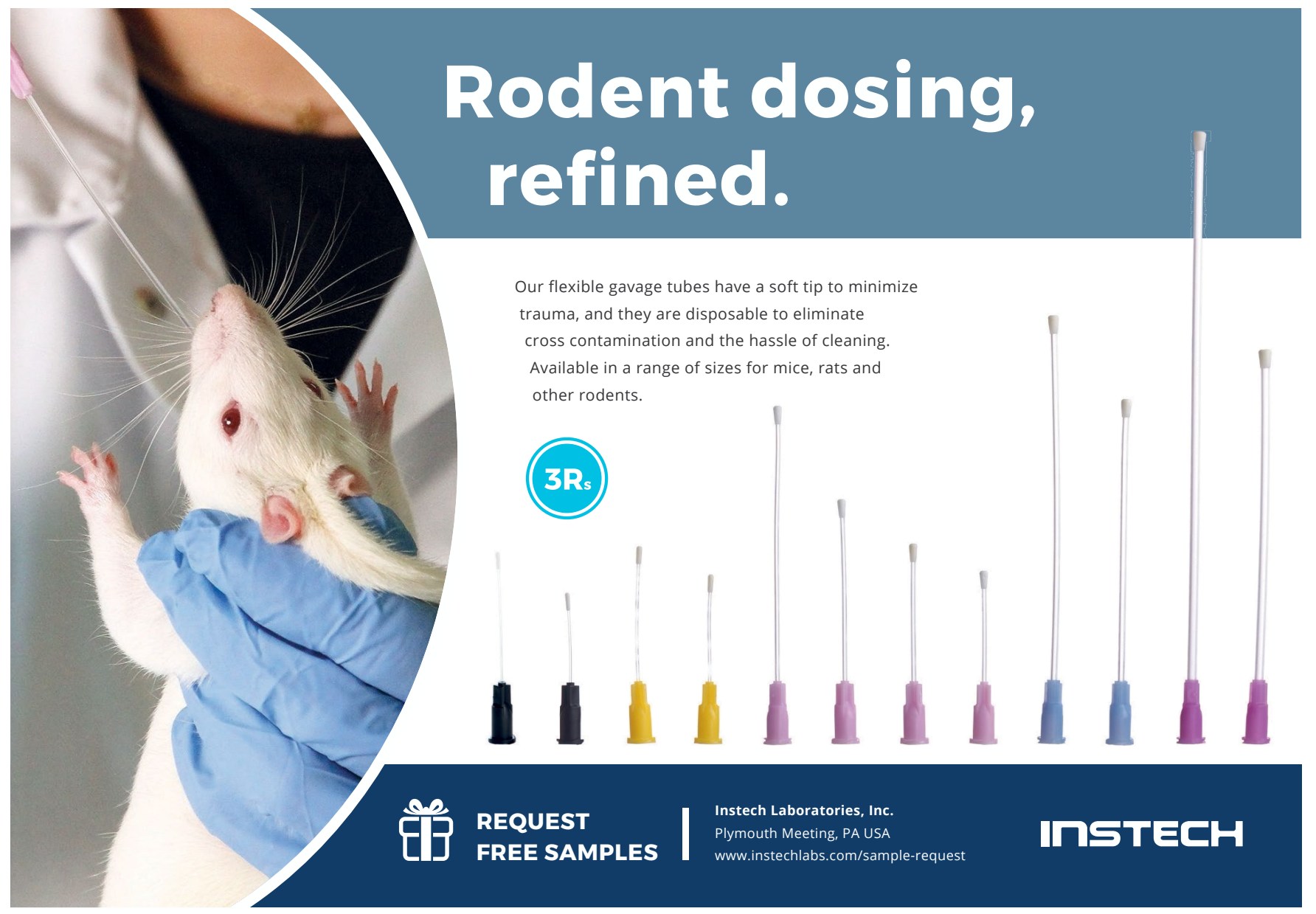

